\title{
Theoretical and Numerical Analyses of Earth Pressure Coefficient along the Centerline of Vertical Openings with Granular Fills
}

\author{
Pengyu Yang ${ }^{1,2}{ }^{-}, \mathrm{Li} \mathrm{Li}^{2, *(\mathbb{D})}$ and Michel Aubertin ${ }^{2}$ \\ 1 School of Architecture and Civil Engineering, Xi'an University of Science and Technology, 58 Yanta Rd., \\ Xi'an 710054, China; pengyu.yang@polymtl.ca \\ 2 Research Institute on Mines and Environment, Department of Civil, Geological and Mining Engineering, \\ École Polytechnique de Montréal, C.P. 6079, Succursale Centre-Ville, Montréal, QC H3C 3A7, Canada; \\ michel.aubertin@polymtl.ca \\ * Correspondence: li.li@polymtl.ca; Tel.: +1-514-340-4711 (ext. 2408)
}

Received: 18 July 2018; Accepted: 13 September 2018; Published: 22 September 2018

\begin{abstract}
Granular filling materials are placed into confining structures for various purposes, including but not limited to silos, trenches, mine stopes, and retaining walls for backfill. Stresses in these backfilled openings are commonly estimated using theoretical arching models, with equations that often involve the earth pressure coefficient $K\left(=\sigma_{\mathrm{h}}^{\prime} / \sigma_{\mathrm{V}}^{\prime}\right)$. Such stress estimation can be dramatically impacted by the magnitude of $K$, but its value remains debatable. Along the centerline of vertical openings with granular cohesionless fills, the value of $K$ is sometimes obtained by Jaky's earth pressure coefficient at rest $K_{0}$, based on the assumption of fixed confining walls, whereas Rankine's active earth pressure coefficient $K_{\mathrm{a}}$ is regarded more suitable for $K$ as claimed by some others. Recent numerical analyses from the authors have shown that the state of stress close to the center of backfilled openings cannot be solely related to wall movement. It was also shown that the $K$ value can vary between $K_{\mathrm{a}}$ and $K_{0}$ in backfilled openings with fixed (immobile) walls, depending on the locations and respective values of fill internal friction angle $\varphi^{\prime}$ and Poisson's ratio $v$. However, none of the existing works have addressed the mechanisms and answered this fundamental but critical question: which value of coefficient $K\left(K_{0}, K_{\mathrm{a}}\right.$, or other) should be used with analytical solutions to assess the stresses in backfilled openings (and why)? After assessing the state of the fill placed in a confined opening, theoretical relationships and specific mechanisms are proposed, for the first time, to evaluate critical values of $v$ and $\varphi^{\prime}$ for defining the at-rest and active states in fills. The approach indicates that when $v$ or $\varphi^{\prime}$ are smaller than or equal to critical values, the value of $K$ near the center line of a backfill opening should be close to $K_{a}$; otherwise, $K$ tends to approach $K_{0}$ defined from $v$. The theoretical analysis is complemented and validated (in part) by numerical simulations. The results also demonstrate that Poisson's ratio can play a major role on the stress distribution within cohesionless fills, and should thus be accurately evaluated.
\end{abstract}

Keywords: backfilled openings; stress state; earth pressure coefficient; Poisson's ratio; internal friction angle; theoretical model; numerical modeling

\section{Introduction}

Granular filling materials are commonly placed inside confining structures for various engineering purposes; such applications include but are not limited to silos, trenches, mine stopes, and backfill retaining walls [1-11]. Upon placement, the fills settle downward due to self-weight, whereas the stiff confining walls tend to keep fills by limiting vertical displacements. Shear stresses develop between the softer fills and stiffer walls, inducing a transfer of stress to the latter. The resulting vertical stress 
reduction (compared to those due to overburden) in the backfill is commonly known as arching. Theoretical methods for evaluating stresses in backfilled openings mostly stem from the arching theory of Janssen [1] proposed to estimate stresses within silos. Marston [3] applied Janssen's arching theory in geotechnique for calculating loads exerted on buried conduits in backfilled trenches. Based on Marston's [3] theory, the vertical $\sigma^{\prime}{ }_{\mathrm{V}}$ and horizontal (lateral) $\sigma_{\mathrm{h}}^{\prime}$ effective stresses within cohesionless fills placed in openings can be estimated as follows:

$$
\begin{gathered}
\sigma \prime_{\mathrm{v}}=\frac{B \gamma}{2 K \tan \delta \prime}\left(1-e^{-2 h K \tan \delta \prime / B}\right) \\
\sigma \prime_{\mathrm{h}}=K \sigma \prime_{\mathrm{v}}
\end{gathered}
$$

where $\gamma\left(\mathrm{kN} / \mathrm{m}^{3}\right)$ represents the fill's unit weight; $B(\mathrm{~m})$ denotes the opening width; $h(\mathrm{~m})$ represents the depth from the backfill top surface; $\delta^{\prime}\left({ }^{\circ}\right)$ denotes the effective internal friction angle of the backfill-wall interfaces. The actual value of $\delta^{\prime}$ is usually regarded as equal to the effective internal friction angle of the fill $\varphi^{\prime}\left({ }^{\circ}\right)$ in the case of mine stopes, because the fill yield tends to occur within fills as rock walls can have very stiff and rough surfaces following production blasting [5,12].

In Equation (1), $K$ represents the earth pressure coefficient that is defined by the ratio of the horizontal over the vertical effective stresses $\left(K=\sigma^{\prime}{ }_{\mathrm{h}} / \sigma^{\prime}{ }_{\mathrm{V}}\right)$. The $K$ value is not an intrinsic material property but serves as a convenient parameter introduced in simplified analyses of the 2D (two-dimensional) stress state in soils and fills.

To estimate stresses in minefill stopes, Marston's [3] solution has been widely used (with or without modifications) $[5,10,13]$. Applying this type of solution requires knowledge of the $K$ value, which largely affects the estimated stress state in various backfilled openings (silo, trench, mine stope, backfill retaining wall, etc.). However, the actual values of $K$ in such openings are still debatable.

When the backfill is deposited after a stope is entirely mined out in the case of isolated stopes, the movement of the wall can be regarded as negligible. Accordingly, the value of $K$ in backfilled stopes is sometimes associated with the earth pressure coefficient at-rest $K_{0}$ [14-20]. However, some numerical simulations and their comparisons with arching solutions have shown that Rankine's active earth pressure coefficient $K_{\mathrm{a}}$ is sometimes more appropriate, especially along the centerline [12,13,21-24]. Some of these numerical analyses have been supported (in part) by laboratory testing results $[16,24,25]$. Other numerical results, including those obtained by Caceres [26], Jahanbakhshzadeh et al. [27], and Yang et al. [28,29], indicate that the $K$ value across backfilled stopes tends to vary, typically between $K_{\mathrm{a}}$ and Jaky's $K_{0}$, depending on the location and values of $\varphi^{\prime}$ and $\nu$. However, none of these investigations addressed the mechanisms controlling the backfill state in openings with fixed confining walls. There is thus a need to establish more specifically why and how the $K$ value varies with the fill properties, specifically $\varphi^{\prime}$ and $v$, and define which coefficient $\left(K_{0}, K_{\mathrm{a}}\right.$, or another value) should be used with analytical solutions to estimate the stresses in backfilled openings. This work aims to clarify this aspect (at least in part) based on theoretical and numerical analyses of stresses along the centerline of openings filled with granular cohesionless materials.

In this paper, the origins and definitions of the at-rest $\left(K_{0}\right)$ and active $\left(K_{\mathrm{a}}\right)$ earth pressure coefficients are first briefly revisited, emphasizing the distinctions between the natural soil state, the states behind retaining walls and in backfilled openings. The state of stress along the vertical centerline (VCL) of backfilled openings is then analyzed by considering its elasto-plastic behavior. This leads to an explicit theoretical relationship and corresponding mechanisms which can be used to identify the state that may prevail within fills. The results of this analysis are compared and partly validated using simulations conducted with FLAC (Fast Lagrangian Analysis of Continua) [30]. 


\section{Theoretical Analyses}

\subsection{State of Stress in Natural Soils and behind Retaining Walls}

In soil mechanics, the state of stress in the soil mass (or fill material) is usually associated with the lateral translations of retaining walls and related to the vertical stress. Three distinct states and corresponding earth pressure coefficients are typically applied in geotechnical engineering for cohesionless soils (fills) to calculate the horizontal stresses [31-33].

The situation is typically described using the conceptual model of a stiff and very thin wall (to minimize disturbance) which is theoretically introduced into an initially at-rest (natural) soil, and then removing the soil on one side of the wall and applying a horizontal force (pressure) to keep the vertical smooth wall in place. When the retaining wall is pushed (sufficiently) against the compressed soil, it may yield and fully mobilize its frictional strength to resist the horizontal movement. This corresponds to a passive state; such condition is not frequently encountered in backfilled openings. When the wall is allowed to move outward, the horizontal stress on this wall is reduced by shear yielding of the soil; the corresponding plastic equilibrium leads to an active state. For cohesionless fills having flat horizontal top surface, the coefficient $K$ can then be represented by Rankine's active earth pressure coefficient $K_{\mathrm{a}}[7,31-33]$ :

$$
K_{a}=\frac{1-\sin \varphi \prime}{1+\sin \varphi \prime}
$$

Another (theoretical) situation arises when the retaining wall is fixed (immobile), without horizontal strain in the soil (fill). The stress state then remains unchanged from that of the natural soil deposit. This corresponds to the at-rest state, with $K=K_{0}$. For loose granular soils, the following semi-empirical relationship is widely used to express the corresponding earth pressure coefficient [34,35]:

$$
\left(K_{0}\right)_{\varphi \prime}=1-\sin \varphi^{\prime}
$$

Alternatively, the value of $K_{0}$ can be estimated, in a more fundamental manner, from Poisson's ratio $v$ using Hooke's law for a linear-elastic, isotropic, and homogeneous material [36,37]:

$$
\left(K_{0}\right)_{v}=\frac{v}{1-v}
$$

\subsection{Fill State in Backfilled Openings}

In the precedent theoretical (idealized) cases, the soil is initially at rest, and would remain at-rest if the retaining wall is immobile. The motion (displacement) of the wall then controls the stress state in the soil. The situation is different in backfilled openings (trenches, silos, mine stopes, and behind fill retaining walls), in which the fill is placed into a preexisting rigid confining structure.

Numerical analyses performed by Sobhi et al. [24] showed that fills near the center of vertical openings can reach an active state because of some local yielding, even if the walls displacement upon filling is negligible. Simulation results reported by Yang et al. [28,29] revealed that the stresses along the VCL of similar openings can be close to an active or at-rest state, depending on the relationships (independent or related) between $\varphi^{\prime}$ and $\nu$. Near the opening walls, the numerical results of Yang et al. [28] showed that the ratios of the minor over major principal effective stresses approach Rankine's active earth pressure coefficient $K_{\mathrm{a}}$, even though the confining walls remain unmoved. Thus, the stress state in such cases cannot be solely linked to the movement of the confining wall(s). However, the mechanism behind this behavior has not been explicitly addressed.

In the following, the state of fills placed in a vertical opening is analyzed based on an elasto-plastic model with varying values of $v$ and $\varphi^{\prime}$. It will be seen that the backfill can approach active or at-rest state along the VCL of a backfilled opening, depending on the relations between the respective values of $\varphi^{\prime}$ and $v$ (even for fixed confining walls). 
When obeying the Mohr-Coulomb elastoplastic criterion, the fill exhibits a linear elastic behavior under relatively small stresses before reaching a yield state. Upon placement, the major $\sigma^{\prime}{ }_{1}$ and minor $\sigma_{3}^{\prime}$ principal stresses along the VCL of the opening, for an elastic state, are $\sigma^{\prime}{ }_{\mathrm{V}}$ and $\left(K_{0}\right)_{\nu} \sigma_{\mathrm{V}}$, respectively. As shown in Figure 1a, two situations can arise for a given friction angle $\varphi^{\prime}$, considering the limit stress state $\left(\sigma_{\mathrm{V}}^{\prime}, K_{\mathrm{a}} \sigma_{\mathrm{v}}^{\prime}\right)$, with the Mohr circle becoming tangential to the Coulomb yield envelope ( $\tau=\sigma$ $\tan \varphi^{\prime}$, where $\tau$ is the maximum shear stress for a given normal stress $\sigma$ ). When $\left(K_{0}\right)_{v} \sigma^{\prime}{ }_{\mathrm{v}} \leq K_{\mathrm{a}} \sigma_{\mathrm{V}}^{\prime}$, the corresponding Mohr circle (dotted line in Figure 1) theoretically exceeds the yield envelope. Since this is not allowed, yielding with plastic strain occurs and the horizontal stress is controlled by the circle tangent to the yield envelope. Such stress state corresponds to an active state in the fill, and can be associated with Rankine's active coefficient $K_{\mathrm{a}}$. On the other hand, if $\left(K_{0}\right)_{v} \sigma_{{ }_{\mathrm{v}}}>K_{\mathrm{a}} \sigma_{\mathrm{v}}$, the Mohr circle (solid line) remains below the Coulomb yield envelope. The backfill along the VCL can then be expected to be near the at-rest (elastic) state (with $\left.K=\left(K_{0}\right)_{v}\right)$. In Figure $1, \varphi_{c}^{\prime}$ and $v_{\mathrm{c}}$ denote the critical values of the fill's internal friction angle $\varphi^{\prime}$ and Poisson's ratio $v$ (defined below).

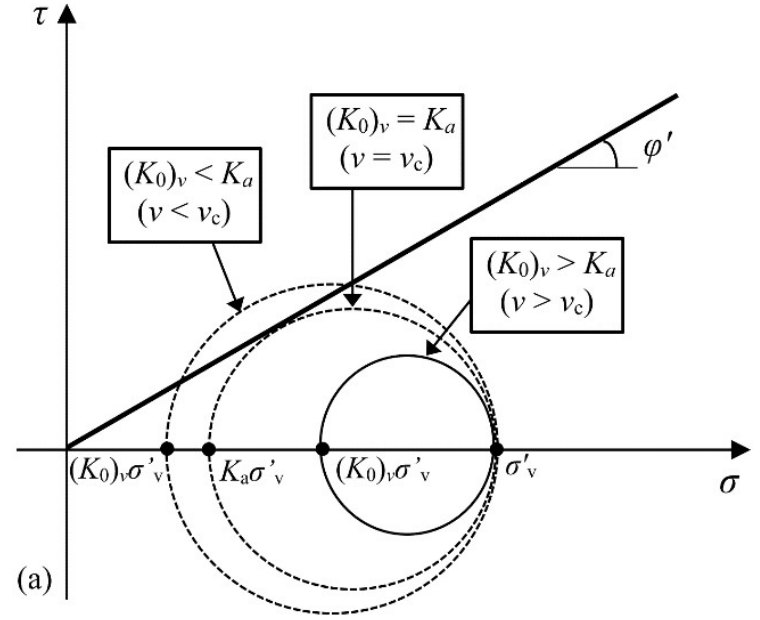

(a)

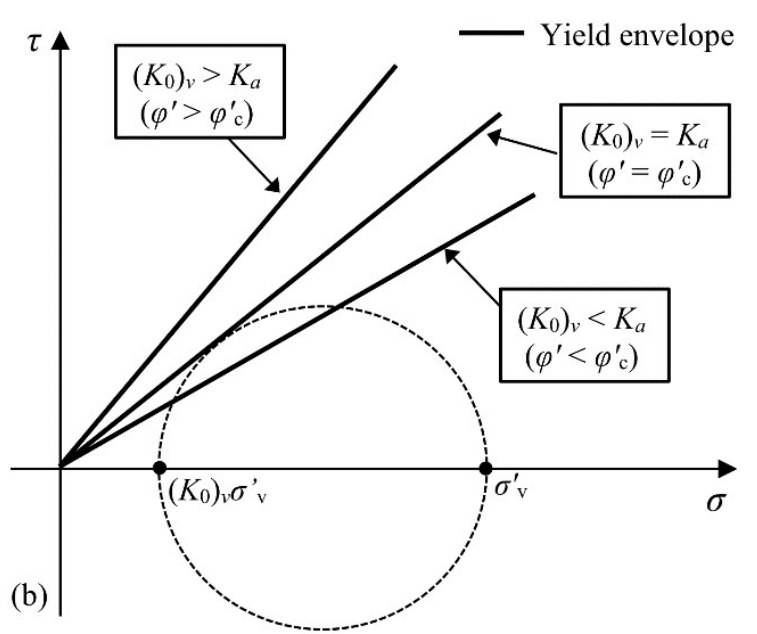

(b)

Figure 1. Stress states in backfills along the vertical centerline (VCL) of the opening illustrated by Mohr-Coulomb planes, with constant (a) internal friction angle $\varphi^{\prime}$ and (b) Poisson's ratio $v$. The dotted line circle indicates an active state while the solid line circle indicates an at-rest state.

Similarly, Figure $1 \mathrm{~b}$ illustrates that, for a given Poisson's ratio $v$, the resulting Mohr circle based on the initial elastic stress state $\left(\sigma_{\mathrm{V}}^{\prime},\left(K_{0}\right)_{v} \sigma_{\mathrm{V}}^{\prime}\right)$ may or may not theoretically exceed the Coulomb yield envelope, depending on the value of $\varphi^{\prime}$. When $\varphi^{\prime}$ is small enough, $\left(K_{0}\right)_{v} \sigma^{\prime}{ }_{\mathrm{V}} \leq K_{\mathrm{a}} \sigma^{\prime}{ }_{\mathrm{V}}$, and the stress state will be active (with $K=K_{\mathrm{a}}$ ). As the value of $\varphi^{\prime}$ increases, $\left(K_{0}\right)_{v} \sigma_{{ }_{\mathrm{V}}}>K_{\mathrm{a}} \sigma^{\prime}{ }_{\mathrm{V}}$, and the backfill remains in an at-rest (elastic) state (with $K=\left(K_{0}\right)_{v}$ ).

For both cases illustrated in Figure $1 \mathrm{a}, \mathrm{b}$ the theoretical condition for distinguishing between the at-rest and active states is given by $\left(K_{0}\right)_{v} \sigma^{\prime}{ }_{\mathrm{V}}=K_{\mathrm{a}} \sigma^{\prime}{ }_{\mathrm{v}}\left(\right.$ or $\left.\left(K_{0}\right)_{v}=K_{\mathrm{a}}\right)$. Combining Equations (2) and (4) leads to the following relationship:

$$
\frac{v}{1-v}=\frac{1-\sin \varphi^{\prime}}{1+\sin \varphi^{\prime}}
$$

For a given friction angle $\varphi^{\prime}$, the critical value of Poisson's ratio $v_{\mathrm{c}}$ of the fill can be given by rearranging Equation (5):

$$
v_{c}=\frac{1-\sin \varphi \prime}{2}
$$

For a given Poisson's ratio $v$, the critical value of the internal friction angle $\varphi^{\prime}{ }_{\mathrm{c}}$ becomes:

$$
\varphi{ }_{\mathrm{v}}^{\prime}=\sin ^{-1}(1-2 v)
$$


Equation (6) can thus be used to calculate the critical values of $\varphi^{\prime}$ or $v$ that define the transition between an at-rest state and active state near the center of backfilled openings with rigid confining walls. This analysis indicates that when $v \leq v_{\mathrm{c}}$ or $\varphi^{\prime} \leq \varphi^{\prime}{ }_{\mathrm{c}}$, the backfill is in an active state because the stress state induces yielding; otherwise, an at-rest state prevails (as illustrated in Figure 1).

Sometimes, the values of angle $\varphi^{\prime}$ and Poisson's ratio $v$ can be linked through a unique (and consistent) value of $K_{0}$ (i.e., $\left.\left(K_{0}\right)_{\varphi^{\prime}}=\left(K_{0}\right)_{v}\right)$, based on Equations (3) and (4) for an elastoplastic model. This would lead to a special situation, as shown in the following relationship [27,37-41]:

$$
v=\frac{1-\sin \varphi^{\prime}}{2-\sin \varphi^{\prime}}
$$

As the $v$ value given by this equation always exceeds that of Equation (6a), the fill state associated with Equation (7) corresponds to an at-rest condition (with $\left.K=\left(K_{0}\right)_{v}=\left(K_{0}\right)_{\varphi^{\prime}}\right)[42,43]$.

The validity of this theoretical analysis is further assessed below using numerical simulations conducted with FLAC 2D.

\section{Numerical Simulations and Comparisons}

\subsection{Numerical Model}

Figure 2a shows a two-dimensional (plane strain conditions) backfilled opening and Figure $2 \mathrm{~b}$ illustrates the corresponding FLAC model [30]. The rock mass is a linear elastic material characterized by a Young's modulus $E_{\mathrm{r}}$ of $30 \mathrm{GPa}$, a unit weight $\gamma_{\mathrm{r}}$ of $27 \mathrm{kN} / \mathrm{m}^{3}$, and a Poisson's ratio $\nu_{\mathrm{r}}$ of 0.25 . The granular cohesionless fill behaves as a Mohr-Coulomb elastoplastic material with a dry unit weight $\gamma$ of $18 \mathrm{kN} / \mathrm{m}^{3}$, zero effective cohesion $c^{\prime}$, and zero dilation angle $\psi$ (ultimate state with non-associated flow rule). The values of the fill Poisson's ratio $v$, internal friction angle $\varphi^{\prime}$, and Young's modulus $E$ vary within a range of values given in Table 1 (which also gives other parameters and identifies simulated cases).

(a)

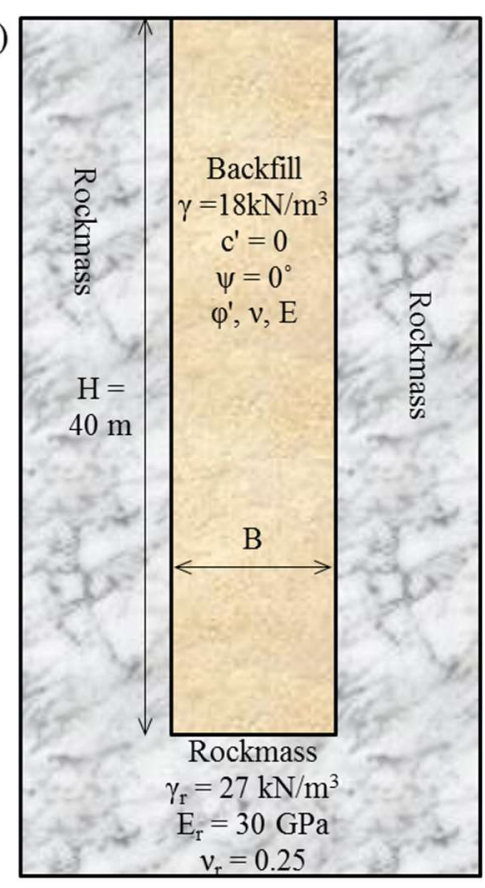

(b)

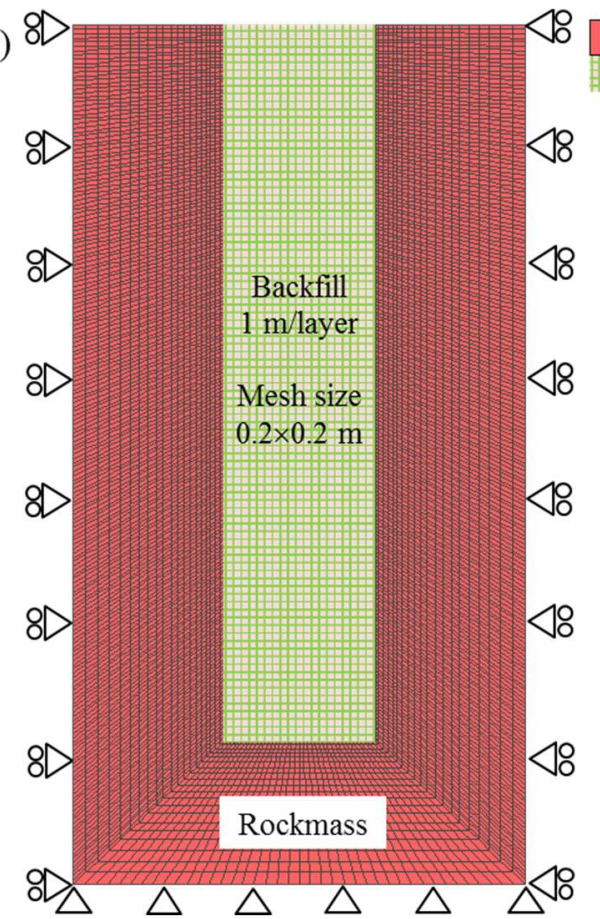

Figure 2. (a) A backfilled opening and (b) the corresponding numerical model. 
Table 1. Geometric and mechanical characteristics of the numerical models simulating the backfilled stopes.

\begin{tabular}{cccccc}
\hline Cases & Figure Reference & $\boldsymbol{B}(\mathbf{m})$ & $\boldsymbol{E} \mathbf{( M P a})$ & Peak $\boldsymbol{\varphi}^{\prime}\left(^{\circ}\right)$ & $v(-)$ \\
\hline 1 & Figure 3a & 4 to 20 & 300 & 30 & 0.2 \\
2 & Figure 3b & 8 & 10 to 1000 & 30 & 0.2 \\
3 & Figure 3c & 8 & 300 & 10 to 45 & 0.2 \\
4 & Figure 3d & 8 & 300 & 30 & 0.001 to 0.499 \\
$5^{*}$ & Figure 4 & 8 & 300 & $10^{\circ}$ to $40^{\circ}$ & 0.452 to 0.263 \\
\hline \multicolumn{5}{c}{}
\end{tabular}

In Figure $2 b$, the two side boundaries of the rock mass are fixed horizontally, while the displacements are restricted in all directions at the base. The opening is first created instantaneously. After the induced displacements are reset to zero, backfilling is performed layer-by-layer ( $1 \mathrm{~m}$ per layer) to a height $(H)$ of $40 \mathrm{~m}$, with an open and horizontal top surface. This progressive filling sequence reduces the effect of the added layers (due to momentum) on the simulated stresses and earth pressure coefficient (see details in Yang [40]). Hence, there is no rock wall closure on the backfill (and no stress imposed by the rock walls to the backfill). This approach is valid for the delayed filling of a single opening, after convergence for stiff rock walls [12].

Sensitivity analyses of the mesh indicate that the $0.2 \times 0.2 \mathrm{~m}$ square mesh elements can be used to model the fills. Interface elements are not used between the walls and backfill, which are considered to be very rough due to blasting (as is typically the case in underground mine stopes) $[5,44]$. Furthermore, numerical results presented by Yang et al. $[28,29]$ have indicated that the roughness of interface elements tends to alter the magnitude of the vertical and horizontal stresses along the vertical centerline of backfilled openings, but it has little impact on the corresponding values of $K$.

\subsection{Theoretical Predictions}

For Cases 1 and 2, the critical Poisson's ratio $v_{\mathrm{c}}$ is 0.25 based on Equation (6a) with $\varphi^{\prime}=30^{\circ}$; the critical friction angle $\varphi^{\prime}{ }_{\mathrm{c}}$ is $36.9^{\circ}$ for $v=0.2$ according to Equation (6b). In these two cases, $v \leq v_{\mathrm{c}}$ or $\varphi^{\prime}<\varphi^{\prime}$, so the backfill along the VCL of the openings can be expected to yield and reach an active state with $K$ close to $K_{\mathrm{a}}=0.33$ (Equation (2) with $\varphi^{\prime}=30^{\circ}$ ).

For Cases 3 with $\varphi^{\prime} \leq \varphi^{\prime}{ }_{\mathrm{c}}=36.9^{\circ}$ (from Equation (6b) with $v=0.2$ ), an active state is anticipated within the yielding fill along the VCL (i.e., $K$ near $K_{\mathrm{a}}$ defined by Equation (2)). For $\varphi^{\prime}>\varphi^{\prime}{ }_{\mathrm{c}}=36.9^{\circ}$, an at-rest state can be expected, and the $K$ value should then approach $\left(K_{0}\right)_{v}=0.25$ (Equation (4) with $v=0.2)$.

For Cases 4 with $v \leq v_{\mathrm{c}}=0.25$ (Equation (6a) with $\varphi^{\prime}=30^{\circ}$ ), an active state is also expected along the VCL of the backfilled opening (i.e., $K$ is close to $K_{\mathrm{a}}=0.33$, with $\varphi^{\prime}=30^{\circ}$ ). For $v>v_{\mathrm{c}}=0.25$, a $K$ value close to $\left(K_{0}\right)_{v}$ (Equation (4)) is anticipated within the fill.

For Cases 5, values of the backfill Poisson's ratio $v$ and internal friction angle $\varphi^{\prime}$ are related according to Equation (7). The theoretical analysis presented above shows that the backfill state should be at-rest, with $K=\left(K_{0}\right)_{v}=\left(K_{0}\right)_{\varphi^{\prime}}$.

\subsection{Numerical Results}

In all simulated cases, the $K$ values were obtained from the ratios of numerical horizontal and vertical stresses. Figure 3 shows the simulated variations of $K$ along the VCL of backfill openings, considering different values for opening width $B$ (Figure 3a; Cases 1), Young's modulus $E$ (Figure 3b; Cases 2), friction angle $\varphi^{\prime}$ (Figure 3c; Cases 3), and Poisson's ratios $v$ of the fills (Figure 3d; Cases 4). 

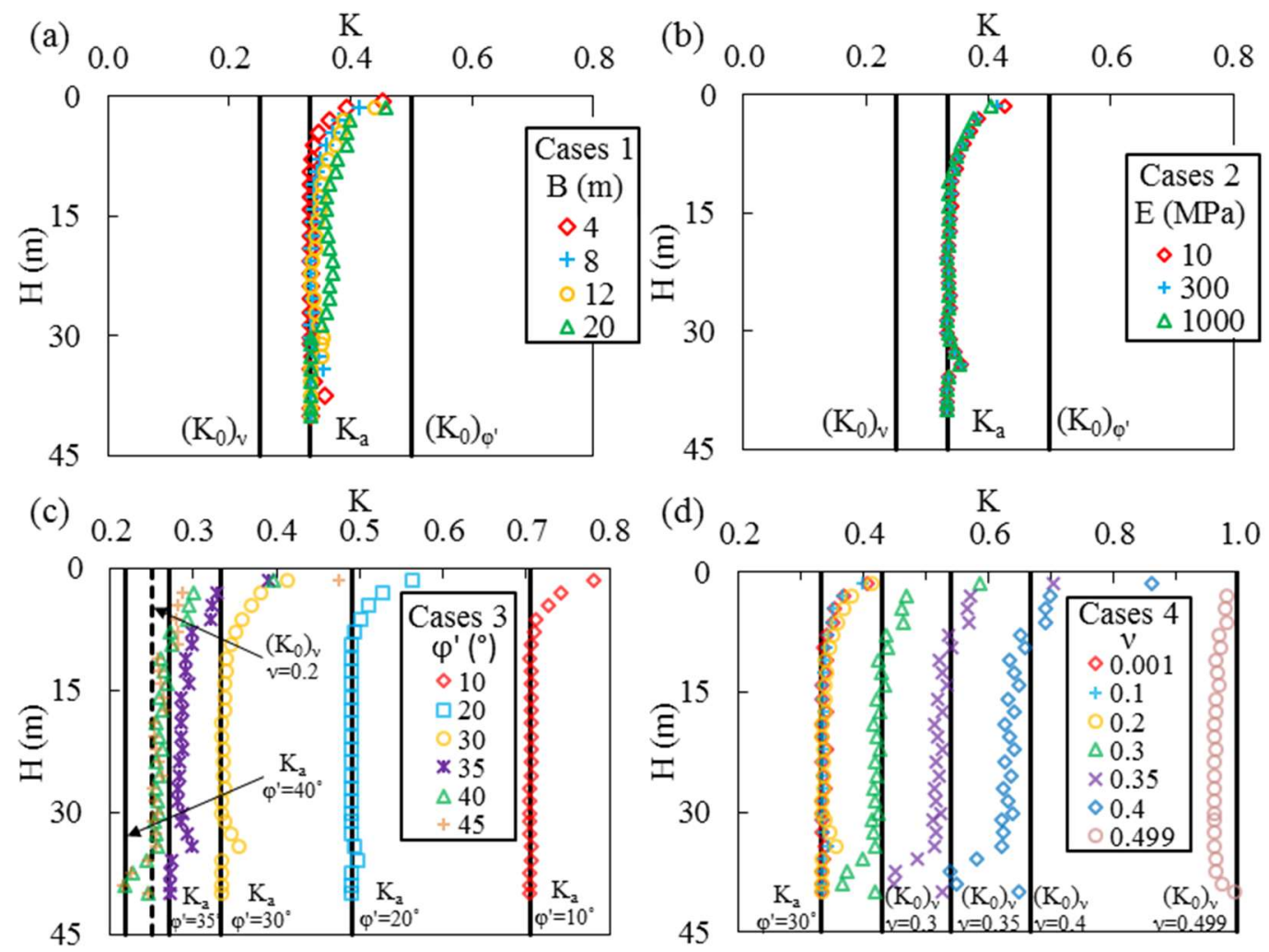

Figure 3. Distribution of $K$ along the VCL of backfilled openings as a function of: (a) $B$ (Cases 1); (b) $E$ (Cases 2); (c) $\varphi^{\prime}$ (Cases 3); and (d) $v$ (Cases 4) (see Table 1 for details).

For Cases 1 (Figure 3a), it is seen that the stress ratio $K$ in the fill along the VCL appears almost unchanged with the variation of the width of opening $B$ (ranging between 4 and $20 \mathrm{~m}$ ). As expected, the $K$ values near the center line of the backfill opening are close to Rankine's active coefficient $K_{\mathrm{a}}$, for $B$ varying between 4 and $20 \mathrm{~m}$ (except near the fill surface).

For Cases 2, Figure $3 b$ illustrates that $K$ along the VCL remains almost constant as the fill modulus $E$ changes between $10 \mathrm{MPa}$ and $1 \mathrm{GPa}$. The stress state near the opening center is known to be almost insensitive to the fill modulus, which also has little effect on the $K$ value (for a range of $E$ varying from $10 \mathrm{MPa}$ to $1 \mathrm{GPa}$ ). The $K$ values obtained from the numerical modeling are close to $K_{\mathrm{a}}$, which is consistent with the respective values of the fill Poisson's ratio and internal friction angle (as predicted above from Equation (6)).

Figure $3 \mathrm{c}$ indicates that as the value of internal friction angle $\varphi^{\prime}$ changes from $10^{\circ}$ to $35^{\circ}$ (Cases 3), the $K$ values near the backfill opening center tend to decrease, but remain fairly around $K_{\mathrm{a}}$, except near the fill top. As the values of $\varphi^{\prime}$ increase to $40^{\circ}$ and $45^{\circ}$, the ratio $K$ continues to decrease slightly and then stays close to a constant value given by $\left(K_{0}\right)_{v}$ (with $v=0.2$ ). These numerical results are also consistent with the theoretical analyses presented above.

Figure $3 \mathrm{~d}$ shows that the $K$ values near the backfilled opening center keep almost unchanged (near $K_{\mathrm{a}}$ ), when Poisson's ratio $v$ varies between 0.001 and 0.2 , except near the top surface of the backfilled opening (Cases 4 ). When the value of Poisson's ratio $v \geq 0.3$, the $K$ value at the center of vertical openings is seen to be a function of Poisson's ratio, with values near $\left(K_{0}\right)_{v}$ (Equation (4)), except near the top surface and bottom of the backfill. Figure $3 \mathrm{~d}$ also illustrates that the $K$ value approaches unity as the value of $v$ goes close to 0.5 (i.e., 0.499), indicating a hydrostatic (isotropic) state. Again, these numerical results agree with the theoretical analyses presented above.

Figure 4 illustrates that, for Cases 5 ( $v$ and $\varphi^{\prime}$ related through Equation (7)), the simulated $K$ values along the VCL are reduced when $\varphi^{\prime}$ is increased (and $v$ is decreased). These simulated values correlate well with $K_{0}$ as the internal friction angle $\varphi^{\prime}$ rises from $10^{\circ}$ to $40^{\circ}$ (with Poisson's ratio $v$ 
ranging between 0.452 and 0.263 ). These simulation results correspond well with those predicted by the theoretical analyses presented above.

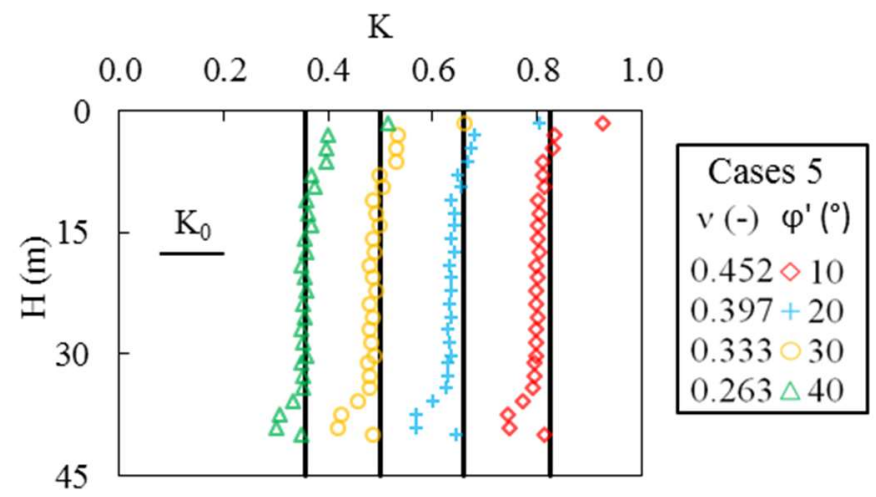

Figure 4. Distribution of $K$ along the VCL of backfilled openings as a function of $\varphi^{\prime}$ and $v$ (Cases 5 in Table 1).

\section{Discussion}

In soil mechanics, the stress state behind a retaining wall is commonly associated with its movement [33]. The soil is initially assumed to be at rest before introducing a (stiff and very thin) retaining wall. An immobile wall is thus sometimes regarded as a necessary and sufficient condition to maintain an at-rest state in the soil. However, it has been shown above that the stress ratio $K$ (and corresponding state) in backfilled openings is not solely associated with the wall movement (see also simulation results from Sobhi et al. [24] and Yang et al. [28,29]). In such openings, yielding of the fill may occur even if the walls are immobile. The theoretical analyses show that the state of stress of backfill at the center of openings also depends on the respective values of $\varphi^{\prime}$ and $v$. This has been confirmed by the numerical results presented above.

The theoretical and numerical analyses presented above would benefit from further validation, based on specific experimental data that comprise all the required parameters, including the vertical and horizontal normal stresses and backfill properties ( $\varphi^{\prime}$ and $v$ ). To the authors' knowledge, such a complete data set does not yet exist. A few results, such as the in-situ measurements performed by Thompson et al. [45], nonetheless indicate that the $K$ value may approach $K_{\mathrm{a}}$ or $K_{0}$, depending on the local conditions in the backfilled stope. These results appear to follow the trends identified by the theoretical and numerical results shown above, particularly for a relatively large $\varphi^{\prime}$ value $\left(=37^{\circ}\right)$, as shown for Cases 3 in Figure 3c. However, a more complete assessment would require additional testing results to specifically determine the backfill Poisson's ratio. In addition, the complex conditions in the field may influence the stress state and related results due to additional factors not considered here (i.e., complex geometry, water pressures, cementation and curing, etc.).

All these indicate that more effort should be made to determine the backfill Poisson's ratio, despite the difficulties raised by accurate measurements. Ongoing study is also being performed by the authors to help obtain the value of $v$ from indirect means.

The numerical analyses performed here consider dry cohesionless filling materials. Previous studies have shown that the generation and dissipation of pore water pressure, cohesion, and cement curing could affect the state of stress developed in backfilled mine stopes [25,43,45]. It has also been shown that a nonzero dilation angle would alter the simulated stress state in backfill openings $[17,25,40]$. Additional work is urged to assess the impact of these additional aspects.

The simulations conducted here assume constant values for Poisson's ratio and Young's modulus of the backfill. In practice, these parameters can vary in the opening due to the changes in falling height or loading associated with the addition of fill layers. It would thus be useful to assess the effect of a spatial variation of the fill properties using numerical simulations and experimental tests. 
In order to analyze the effect of parameters of interest, the parameter of interest was treated as a variable while other parameters were kept constant (see Cases 1-4 in Table 1). The values of $v$ and $\varphi^{\prime}$ were varied simultaneously in Cases 5. Additional work is required to check the validity of the simulated outcomes when two or more parameters are varied at the same time.

The results presented above are based on plane strain conditions, thus corresponding to openings with very long third dimensions. It is known that the magnitude of arching may be under-predicted by plane strain models. Additional work is needed to evaluate the effect of the third dimension, to complement the recent work of Jahanbakhshzadeh [43].

It should be noted that the stress paths and the intermediate state of fills are not considered here. Subsequently, the fill state depends solely on the relationship between $v$ (an elastic constant) and $\varphi^{\prime}$ (a yield parameter) in an elasto-plastic Mohr-Coulomb framework. More representative models are required to better represent the characteristics of fills placed in various openings [46].

The numerical results indicate that the value of the stress ratio $K$ along the centerline can be different near the very top and bottom of backfilled openings. This is related to the abrupt change of the local characteristics (material properties and stress state), which may also cause numerical instability close to these boundaries. Additional work, such as laboratory tests, is required to better investigate this aspect.

As mentioned previously, yield can occur due to the deviatoric stresses when the values of $\varphi^{\prime}$ or $v$ are smaller than or equal to their critical values $\varphi_{c}^{\prime}$ or $v_{\mathrm{c}}$, respectively. The corresponding $K$ can then be expressed using Rankine's active earth pressure coefficient $K_{a}$ (as a function of $\varphi^{\prime}$ ). When the values of $\varphi^{\prime}$ or $v$ are greater than their critical values, $K$ is then linked to the Poisson's ratio $v$ through $\left(K_{0}\right)_{v}$. An exception is when $\varphi^{\prime}$ or $v$ are related to each other through Equation $(7)\left(K=\left(K_{0}\right)_{v}=\left(K_{0}\right)_{\varphi^{\prime}}\right)$.

Finally, it is worth recalling that the internal friction angle $\varphi^{\prime}$ of soils (and filling materials) is commonly determined from usual testing, while their Poisson's ratio $v$ is difficult to measure. Several expressions (somewhat similar to Equation (7)) have thus been proposed to estimate the value of $v$ from that of $\varphi^{\prime}$ through their respective connections with $K_{0}$ (Equations (3) and (4)) [37,38,40,41,47]. Despite some superficial similarities, these expressions are fundamentally different from the proposed Equations (5) and (6), which serve to explain why and when the value of $K$ should be equal to $K_{0}$ or $K_{a}$ to assess stresses in backfilled openings from analytical solutions.

\section{Conclusions}

For granular cohesionless fills, the analytical and numerical analyses presented above show that either an active $\left(K_{\mathrm{a}}\right)$ or an at-rest $\left(K_{0}\right)$ stress state may exist at the center of backfill openings with stiff and fixed confining walls, associated with the respective values of fill Poisson's ratio $v$ and internal friction angle $\varphi^{\prime}$. An original relationship (Equation (6)) between $\varphi^{\prime}$ and $v$, and the corresponding mechanisms, are developed to define when $K_{\mathrm{a}}$ or $K_{0}$ should be used (based on the Mohr-Coulomb elasto-plastic criterion). Theoretically, the earth pressure coefficient $K$ near the centerline of a vertical backfill opening can be expected to be near Rankine's active coefficient $K_{\mathrm{a}}$ when $\varphi^{\prime}$ and $v$ are smaller than or equal to critical values (given by Equations (6a) and (6b), respectively). Otherwise, $K$ should be close to the earth pressure coefficient at-rest $K_{0}$ (Equation (4)). The theoretical analysis was validated, in part, by numerical modeling performed with FLAC. The results presented here also highlight the importance of an accurate evaluation of the Poisson's ratio for granular cohesionless fills.

Author Contributions: Funding acquisition, L.L., M.A., and P.Y.; Investigation, P.Y., L.L., and M.A.; Methodology, P.Y., L.L., and M.A.; Project administration, L.L.; Software, P.Y.; Supervision, L.L. and M.A.; Validation, P.Y.; Writing—original draft, P.Y.; Writing—review \& editing, P.Y., L.L., and M.A.

Funding: This research was funded by the Natural Sciences and Engineering Research Council of Canada (402318), Institut de recherche Robert-Sauvé en santé et en sécurité du travail (2013-0029), Fonds de recherche du Québec-Nature et Technologies (2015-MI-191676), Mitacs Elevate Postdoctoral Fellowship (IT08484), and industrial partners of the Research Institute on Mines and Environment (RIME UQAT-Polytechnique; http: //rime-irme.ca/).

Conflicts of Interest: The authors declare no conflict of interest. 


\section{References}

1. Janssen, H.A. Versuche uber getreidedruck in silozellen. Z. Ver. Dtsch. Ing. 1895, 39, 1045-1049.

2. Butenweg, C.; Rosin, J.; Holler, S. Analysis of cylindrical granular material silos under seismic excitation. Buildings 2017, 7, 61. [CrossRef]

3. Marston, A. The theory of external loads on closed conduits in the light of latest experiments. In Proceedings of the 9th Annual Meeting of the Highway Research Board, Washington, DC, USA, 12-13 December 1929.

4. Kim, S.; Lee, K. Field performance of recycled plastic foundation for pipeline. Materials 2015, 8, $2673-2687$. [CrossRef]

5. Aubertin, M.; Li, L.; Arnold, S.; Belem, T.; Bussière, B.; Benzaazoua, M.; Simon, R. Interaction between backfill and rock mass in narrow stopes. In Proceedings of the 12th Panamerican Conference on Soil Mechanics and Geotechnical Engineering, Essen, Germany, 22-26 June 2003.

6. Liu, L.; Song, K.-I.; Lao, D.; Kwon, T.-H. Rheological properties of cemented tailing backfill and the construction of a prediction model. Materials 2015, 8, 2076-2092.

7. Paik, K.H.; Salgado, R. Estimation of active earth pressure against rigid retaining walls considering arching effects. Geotechnique 2003, 53, 643-654. [CrossRef]

8. Zhang, X.; Lin, J.; Liu, J.; Li, F.; Pang, Z. Investigation of hydraulic-mechanical properties of paste backfill containing coal gangue-fly ash and its application in an underground coal mine. Energies 2017, 10, 1309. [CrossRef]

9. Zhao, T.; Zhang, Y.; Zhang, Z.; Li, Z.; Ma, S. Deformation monitoring of waste-rock-backfilled mining gob for ground control. Sensors 2017, 17, 1044. [CrossRef] [PubMed]

10. Tien, H.-J. A Literature Study of the Arching Effect. Master's Thesis, Massachusetts Institute of Technology, Cambridge, MA, USA, 1996.

11. Livingston, B.; Ravichandran, N. Properties of shredded roof membrane-sand mixture and its application as retaining wall backfill under static and earthquake loads. Recycling 2017, 2, 8. [CrossRef]

12. Li, L.; Aubertin, M.; Simon, R.; Bussière, B.; Belem, T. Modelling arching effects in narrow backfilled stopes with FLAC. In Proceedings of the 3th International FLAC Symposium, Sudbury, ON, Canada, 21-24 October 2003.

13. Li, L.; Aubertin, M.; Belem, T. Formulation of a three dimensional analytical solution to evaluate stresses in backfilled vertical narrow openings. Can. Geotech. J. 2005, 42, 1705-1717. [CrossRef]

14. Helinski, M. Mechanics of Mine Backfill. Ph.D. Thesis, University of Western Australia, Perth, Australia, 2007.

15. Pirapakaran, K.; Sivakugan, N. Arching within hydraulic fill stopes. Geotech. Geol. Eng. 2007, 25, $25-35$. [CrossRef]

16. Pirapakaran, K.; Sivakugan, N. A laboratory model to study arching within a hydraulic fill stope. Geotech. Test. J. 2007, 30, 496-503.

17. Fahey, M.; Helinski, M.; Fourie, A. Some aspects of the mechanics of arching in backfilled stopes. Can. Geotech. J. 2009, 46, 1322-1336. [CrossRef]

18. Singh, S.; Sivakugan, N.; Shukla, S.K. Can soil arching be insensitive to $\phi$ ? Int. J. Geomech. 2010, 10, $124-128$. [CrossRef]

19. Singh, S.; Shukla, S.K.; Sivakugan, N. Arching in inclined and vertical mine stopes. Geotech. Geol. Eng. 2011, 29, 685-693. [CrossRef]

20. Ting, C.H.; Shukla, S.K.; Sivakugan, N. Arching in soils applied to inclined mine stopes. Int. J. Geomech. 2011, 11, 29-35. [CrossRef]

21. Li, L.; Aubertin, M. Influence of water pressure on the stress state in backfill with cohesionless stopes. Geotech. Geol. Eng. 2009, 27, 1-11. [CrossRef]

22. Li, L.; Aubertin, M. A three-dimensional analysis of the total and effective stresses in submerged backfilled stopes. Geotech. Geol. Eng. 2009, 27, 559-569. [CrossRef]

23. Sobhi, A.M.; Li, L.; Aubertin, M. Numerical investigation of the lateral earth pressure coefficient along the VCL of vertical backfilled stopes. In Proceedings of the 67th Canadian Geotechnical Conference, Regina, SK, Canada, 28 September-1 October 2014.

24. Sobhi, A.M.; Li, L.; Aubertin, M. Numerical investigation of the earth pressure coefficient along the center line of backfilled stopes. Can. Geotech. J. 2017, 54, 138-145. [CrossRef]

25. Li, L.; Aubertin, M. Numerical investigation of the stress state in inclined backfilled stopes. Int. J. Geomech. 2009, 9, 52-62. [CrossRef] 
26. Caceres, C. Effect of Backfill on Longhole Open Stoping. Master's Thesis, University of British Columbia, Vancouver, Canada, 2005.

27. Jahanbakhshzadeh, A.; Aubertin, M.; Li, L. A new analytical solution for the stress state in inclined backfilled mine stopes. Geotech. Geol. Eng. 2017, 35, 1151-1167. [CrossRef]

28. Yang, P.Y.; Li, L.; Aubertin, M. Stress ratios in entire mine stopes with cohesionless backfill: A numerical study. Minerals 2017, 7, 201. [CrossRef]

29. Yang, P.Y.; Li, L.; Aubertin, M. Numerical analyses of the earth pressure coefficient along the vertical centerline in mine stopes with cohesionless backfill. In Proceedings of the 19th International Conference on Soil Mechanics and Geotechnical Engineering, Seoul, Korea, 17-22 September 2017.

30. Itasca. FLAC-Fast Lagrangian Analysis of Continua; User's Guide; Itasca Consulting Group: Minneapolis, MN, USA, 2011.

31. Lambe, T.W.; Whitman, R.V. Soil Mechanics; Massachusetts Institute of Technology: Cambridge, MA, USA, 1979.

32. Bowles, J.E. Physical and Geotechnical Properties of Soils, 2nd ed.; McGraw-Hill: New York, NY, USA, 1984.

33. McCarthy, D.F. Essentials of Soil Mechanics and Foundations: Basic Geotechnics, 7th ed.; Prentice Hall: Upper Saddle River, NJ, USA, 2007.

34. Jaky, J. The coefficient of earth pressure at-rest. J. Soc. Hung. Arch. Eng. 1944, 78, 355-358.

35. Jaky, J. Pressure in silos. In Proceedings of the 2nd International Conference on Soil Mechanics and Foundation Engineering, Rotterdam, The Netherlands, 21-30 June 1948.

36. Blight, G. Geotechnical Engineering for Mine Waste Storage Facilities; CRC Press: London, UK, 2010.

37. Federico, A.; Elia, G. At-rest earth pressure coefficient and Poisson's ratio in normally consolidated soils. In Proceedings of the 17th International Conference on Soil Mechanics and Geotechnical Engineering: The Academia and Practice of Geotechnical Engineering, Alexandria, Egypt, 5-9 October 2009.

38. Duncan, J.M.; Bursey, A. Soil modulus correlations. In Proceedings of the Foundation Engineering in the Face of Uncertainty: Honoring Fred H. Kulhawy, San Diego, CA, USA, 3-7 March 2013.

39. Falaknaz, N.; Aubertin, M.; Li, L. Numerical investigation of the geomechanical response of adjacent backfilled stopes. Can. Geotech. J. 2015, 52, 1507-1525. [CrossRef]

40. Yang, P.Y. Investigation of the Geomechanical Behavior of Mine Backfill and Its Interaction with Rock Walls and Barricades. Ph.D. Thesis, Polytechnique Montreal, Montreal, QC, Canada, 2016.

41. Yang, K.H.; Liu, C.N. Finite element analysis of earth pressures for narrow retaining walls. J. Geo Eng. 2007, 2, 43-52.

42. Falaknaz, N. Analysis of the Geomechanical Behavior of Two Adjacent Backfilled Stopes Based on Two and Three Dimensional Numerical Simulations. Ph.D. Thesis, Polytechnique Montreal, Montreal, QC, Canada, 2014.

43. Jahanbakhshzadeh, A. Analyse du Comportement Géomécanique des Remblais Miniers Dans des Excavations Souterraines Inclinées. Ph.D. Thesis, Polytechnique Montreal, Montreal, QC, Canada, 2016.

44. Liu, G.S.; Li, L.; Yang, X.C.; Guo, L.J. A numerical analysis of the sress distribution in backfilled stopes considering nonplanar interfaces between the backfill and rock walls. Int. J. Geotech. Eng. 2016, 10, 271-282. [CrossRef]

45. Thompson, B.D.; Grabinsky, M.W.; Bawden, W.F. In situ measurements of cemented paste backfill at Cayeli Mine. Can. Geotech. J. 2012, 49, 755-772. [CrossRef]

46. Li, L.; Aubertin, M.; Shirazi, A. Implementation and application of a new elasto-plastic model based on a multiaxial criterion to assess the stress state near underground openings. Int. J. Geomech. 2010, 10, 13-21. [CrossRef]

47. Duncan, J.M.; Williams, G.W.; Sehn, A.L.; Seed, R.B. Estimation earth pressures due to compaction. J. Geotech. Eng. 1991, 117, 1833-1847. [CrossRef]

(C) 2018 by the authors. Licensee MDPI, Basel, Switzerland. This article is an open access article distributed under the terms and conditions of the Creative Commons Attribution (CC BY) license (http://creativecommons.org/licenses/by/4.0/). 